\title{
Midwives' experiences of transitioning into private practice with visiting access in Australia: A qualitative descriptive study
}

\begin{abstract}
Background: A National review of maternity services in Australia in 2009 resulted in legislative changes which provided midwives with an unprecedented opportunity to offer continuity of care as a private practitioner with visiting access to a public maternity hospital. However, very few midwives have taken up this opportunity.
\end{abstract}

Aim: To explore the experiences of midwives who transitioned into private practice with visiting access to a public hospital.

Method: Using a qualitative descriptive approach, six midwives participated in digitally recorded in-depth interviews. Data was analysed using thematic analysis.

Findings: Transitioning to private practice enabled midwives to align their core midwifery values with their practice. Midwives reported taking 'a leap of faith' by venturing into private practice. Although seeking visiting access and running a small business was initially daunting, midwives were rewarded by being able to practice autonomously and provide continuity of woman centred care within a caseload model. The legislative restrictions, especially around employing other midwives posed significant challenges.

Discussion and conclusions: Private practice with visiting access provided midwives with a service model that aligned their core midwifery values with their clinical practice. The model facilitated their ability to work as lead care professionals, provide woman centred care and access a collaborative network of health care professions. However, the midwives continued to experience structural barriers that threaten the scalability and sustainability of the model. 
Structural barriers to midwives working to their full scope of practice and in alignment with a midwifery philosophy are a global issue. Further reforms are needed.

KEYWORDS: Private practice; midwives; Visiting access; Continuity of care;

\subsection{INTRODUCTION}

Midwifery continuity of care offers women the opportunity to have a 'known' midwife (no more than three midwives) across pregnancy, birth and the early parenting period for up to six weeks postpartum (Tracy et al., 2014). Despite compelling high-level international evidence of the benefits of midwifery continuity of care for childbearing women and their newborns (Sandall, Soltani, Gates, Shennan, \& Devane, 2016), maternity services in Australia are predominately provided in acute care hospitals within a fragmented medical model. It is estimated that less than $10 \%$ of women in Australia have access to midwifery continuity of care (Dawson, Newton, Forster \& McLachlan, 2015a). The majority of midwifery continuity of care provided is through hospital based, publicly funded midwifery group practices (MGP). Women may also access midwifery continuity of care through a private practice midwife. Within the private midwifery model, pregnant women engage with their own midwife who provides the full scope of midwifery care across pregnancy, birth and early parenting on a fee for service basis. The National Maternity Services Review identified that private midwifery offers an important contribution to increasing access for women to midwifery continuity of care (Commonwealth of Australia, 2009). Subsequent legislative changes aimed to increase women's access to this model (Commonwealth of Australia, 2011). These changes included granting private midwives' access to the Pharmaceutical Benefits Scheme (PBS) to enable them to prescribe medications and a Commonwealth subsidised professional indemnity 
insurance. In addition, women could claim a financial rebate using the Medicare Benefits Scheme (MBS) for the fees charged by a midwife in private practice. Provisions were also made for public hospitals to provide visiting access to private practice midwives (Commonwealth of Australia, 2011). Visiting access or 'visiting rights' as it is commonly referred to, enables the private midwife to provide labour and birth care following admission to hospital, thereby assuring continuity of carer for the woman regardless of the place of birth.

In order to obtain access to systems enabling fee rebates for services (MBS), prescribing rights (PBS), subsidised professional indemnity insurance and visiting access, midwives needed a special endorsement. The criteria for endorsement were current general registration as a midwife in Australia with no restrictions on practice; at least three years full time clinical midwifery experience (5000 hours); demonstrated competence in working across the full scope of midwifery practice; completion of an approved professional practice review program; and completion of an Australian Nurses and Midwives Accreditation Council (ANMAC) approved prescribing course (NMBA, 2017).

Despite the 2010 maternity reforms, very few Australian States and Territories have facilitated visiting access for private midwives (Fenwick, Brittain, \& Gamble, 2017) and the number of midwives in private practice remains low. The Nurses and Midwives Board of Australia (NMBA) registrant data (NMBA, 2019) reported that there were 509 'endorsed midwives', the latest available Nursing and Midwifery Workforce report (Australian Institute of Health and Welfare, 2016) published the year before, stated there were only 274 selfemployed midwives in Australia. Whilst private practice is not the only option to provide 
midwifery continuity of care, the model offers an important contribution to increasing woman's choice and access to a known carer.

A search of the literature exploring midwives' experiences of transitioning into private practice was undertaken using Scopus, CINAHL, Proquest, and Informit databases. The search was conducted sequentially using the search terms Midwi*, "private practice", independent, "self-employed" and (transit*, mov* or start*). No research studies examining midwives' experiences of this phenomena were identified. However, five narrative texts, predominately derived from the personal experiences of the authors were retrieved (Davis, 1995; Gamble, 1993a, 1993b; Jenkin, 2013; Smith, 1994). The article by Jenkin (2013) offered the perspective of the experience of moving into private practice following the 2010 maternity reforms, however Jenkin had not obtained visiting access to a hospital. The remaining four articles were published in the 1990's (Davis, 1995; Gamble, 1993a, 1993b; Smith, 1994) prior to the maternity reforms enabling access to MBS, PBS and provisions for visiting access for private midwives. Attaining visiting access to a hospital is essential for private practice midwives as this is the only way to ensure continuity of care can be provided regardless of the place of birth. The literature review identified a substantial gap in research about the experiences of midwives providing continuity of care within private midwifery models that incorporate visiting access. Investigating the enabling factors and challenges for the early adopters of midwifery private practice with hospital visiting access, will facilitate identification of the changes required for the legislative reforms to be fully utilised and should increase women's access to midwifery continuity of care in Australia.

\subsection{AIM}


The aim of this study was to investigate the experiences of midwives transitioning to private practice with visiting access. The specific objectives were to explore:

- midwives motivation for transitioning into private midwifery practice

- enablers that facilitated and sustained the transition into private practice with visiting access, and

- challenges encountered by midwives

\subsection{METHOD}

A qualitative descriptive approach was used. Qualitative description provided an appropriate framework that enabled researchers to stay close to the data, offering a rich description of the meaning the participants attribute to phenomena under study (Sandelowski, 2000). As highlighted by Neergaard, Olesen, Andersen, and Sondergaard (2009), qualitative description is especially helpful when participant views of a particular narrow topic are sought.

\subsection{Ethical considerations}

Ethics approval was granted by the University's Human Ethics Committee (Ref No: NRS/27/13/HREC). Although pseudonyms were assigned, anonymity of participants was recognised by the researchers as potentially challenging due to the small number of privately practicing midwives with visiting access throughout Australia. This was openly discussed with the midwives before the process of consent was finalised. To safeguard anonymity the researchers involved in analysing the data worked only with the de-identified data set and the details of the state or health service have been withheld. All raw data is securely stored on a password locked computer and managed in accordance with NHMRC guidance (NHMRC, 2014). 


\subsection{Participants and recruitment}

Midwives with visiting access were purposefully selected based on the specific nature of their recent experience of commencing private practice and obtaining visiting access to a public hospital. Inclusion criteria for the study consisted of midwives who were currently in private practice; had met (and maintained) requirements for Medicare eligibility; had recent firsthand experience of transitioning into midwifery private practice (within the past two years); and had visiting access to a public hospital. At the time of data collection, only two public hospitals in Australia had implemented visiting access for private practice midwives with a total of eleven midwives working in this way. The chosen site represented the largest proportion of midwives with visiting access. In addition, the midwives with visiting access at this site were from several different private practices. All privately practicing midwives with admitting access to this large tertiary maternity unit were invited to participate $(n=6)$.

\subsection{Participant characteristics}

The six participants were all women, aged between 35 and 55 years, with 13 to 23 years of midwifery experience (see Table 1). The midwives' pathway to registration was varied. Four midwives had obtained their initial midwifery qualification in Australia, one in the United Kingdom (UK) and one in New Zealand. All of the midwives had completed midwifery postgraduate studies in pharmacology, diagnostics and screening to meet requirements for notation as a 'midwife endorsed to prescribe scheduled medicines'. At the time of data collection, the six midwives' current context of practice was within private midwifery group practices. The midwives primarily provided continuity of midwifery care as the 'named midwife' for a caseload of women across pregnancy, labour, birth and the early transition to motherhood (usually six weeks post birth) for women planning to birth in hospital or at home. 
Participants were provided with a verbal and written overview of the study and an opportunity to ask questions and seek clarification. Following verbal consent, a convenient time and place was organised to conduct a digitally recorded face-to-face interview.

\subsection{Data collection}

The interview guide reflected the research objectives based on the expertise of the research team and was broad and exploratory in nature. Interviews were conducted by a postgraduate research student under the supervision of two members of the research team. Prior to conducting the semi-structured interview, written consent was obtained. Interviews varied from 45 to 90 minutes in length and took place in the midwife's own private practice. This location minimised any disruption or potential inconvenience for the midwife. Interviews commenced with each participant being asked a broad question about the decision to become a midwife, providing opportunity for the midwife to ease into the interview. A conversation style was adopted to facilitate rapport with the midwives, enabling more probing questions to emerge from the natural flow of conversation. For example, "So I guess we've talked a little bit about your experiences of gaining visiting rights. So you said a little bit about what that means to you - you felt like you were coming home. Can you tell me a little bit more about this? What was happening that you didn't feel like you were at home but now you are?"

\subsection{Data analysis}

A professional transcription service was employed to transcribe the interview data. The interviews were transcribed verbatim and provided as Word documents. Thematic analysis was used to analyse the data set. The process commenced with listening to each of the 
recordings to provide context of voice, tone and emotion. The transcripts were subsequently checked against the recording to ensure accuracy. Each transcript was then read a number of times. During this process, thoughts and feelings of the primary researcher were documented in a memo type approach to facilitate reflexivity. The transcripts were then placed on A3 size paper to allow room for more extensive notes to be written beside the text. As suggested by Sandelowski (2000), the process of line-by-line analysis was commenced. Here the aim was to identify words, phrases, sentences and sections with similar meaning. Following initial analysis of the first two transcripts by the first author, the research team met to discuss, share and further interrogate the data. The same process was repeated with the next two transcripts. It was at this stage that 'like concepts' started to be grouped together. The research team then meet again and using a 'mind mapping' exercise, further explored and clarified concepts and their groupings, facilitating a more in-depth description of the data and an agreement on the themes and their subthemes. The process was repeated with the final two transcripts. Relationships between themes were then explored producing a pattern that represented a description of how midwives transitioned to private midwifery practice with visiting access.

\subsection{Trustworthiness}

Trustworthiness, which speaks to the credibility of the analysis process, was safeguarded throughout data analysis. With the intent of ensuring the findings stayed true to the data set and reflected the voice of the midwives, data interpretation was continually checked between the first author and other members of the research team. The research team consisted of two senior researchers with expertise in qualitative research and strong clinical backgrounds including experience in midwifery private practice and an early career 
postgraduate research student, also with extensive clinical background including private practice. The decision-making process around data grouping was documented within comprehensive audit trails (see Table 2 for an example of an audit trail) and findings were presented to peers for discussion during other research meetings.

\subsection{FINDINGS}

Thematic analysis of the interview data resulted in the emergence of five themes. Underpinning the midwives' journey into private practice was the theme labelled 'Women centred care: The core of my midwifery values'. This major theme also drove the four associated themes. The first three were titled 'with-system versus with-woman: a misaligned practice context'; 'maternity reforms: taking advantage of new opportunities' and 'private midwifery practice: risk, uncertainty and courage'. The fourth theme labelled 'on the other side: triumphs and tribulation of private practice' was made up of two subthemes 'private practice with visiting access is fantastic' and 'still constrained by the system'. Together these themes describe the midwives' experience of transitioning into private practice with visiting access.

\subsection{Woman centred care: The core of my midwifery values}

The midwives' story of transition to private practice needs to be contextualised within their midwifery values. This central theme provides the backdrop to understanding why the midwives embarked on their journey into private practice, their decision making throughout the journey and the pillar by which the midwives measured their achievements. There were three underpinning core values shared by each of the midwives: women should have access to one-to-one midwifery care throughout pregnancy, birth and early parenting continuum; 
midwives should be able to work to the full scope of midwifery practice; and the woman's choices should always be central to the care provided. These values were predominantly expressed implicitly throughout the data, however, were perhaps best highlighted by Debbie when she said:

"It's about providing that care from early pregnancy right through to six weeks. It's about relationships with women but more than anything it's about that being with, being there for a woman and having her as your sole focus."

\subsection{2 'With system' versus 'with woman': A misaligned practice context}

This major theme described the incongruence between the midwives practice setting and their core value system and, as such, explained what drove the midwives search for opportunities to work within a model that aligned with their midwifery beliefs. Each of the midwives described the context of their midwifery practice prior to their decision to move into private practice. Many of the comments were negative, reflecting the midwives view that hospital-based employment restricted their ability to provide woman centred care and practice to their full scope. Central to this misalignment was the experience of a dominant systems-focussed, fragmented model of care. As Ellie highlighted, "It's - that the hospital or the institutions or the doctors or the midwives are at the centre of care even - and that the woman is not". While the midwives verbalised their "love" of midwifery, they experienced an ongoing frustration at what they saw as a "discrepancy" between what they understood as good for women, good for birth and "what actually happened in practice within the fragmented system" (Amy). Within the context of a fragmented maternity system, the midwives felt constrained and increasingly frustrated by their inability to practice 
autonomously. The midwives spoke of "not being allowed" to use skills such as suturing, cannulation or prescribing and how they experienced a sense of being "disrespected" as a result.

Experiencing dissonance of this nature fuelled the midwives desire to seek out opportunities to work within a model that aligned with their core values. At some stage during the search for their "midwifery home", each of the midwives migrated to employment within a hospitalbased midwifery group practice (MGP). MGP provided an opportunity to more readily use their full scope of practice and provide one-to-one care for women. As Debbie highlighted, "The MGP for me then, was the opportunity to live the dream. To be that midwife and to be able to provide that degree and level of care". For Candy, the MGP provided a sense of independence, reigniting her passion for midwifery; "I actually began to love midwifery again". However, despite hospital based MGP providing a context more aligned with their core values and beliefs, the midwives still expressed a level of frustration at their continued inability to practice autonomously and keep the woman at the centre of care. Amy summed this sentiment up when she said, "Within the public system you can't really work to your full scope. You're still limited by policies and guidelines rather than woman's choice". Ultimately, the continued discord resulted in the midwives ongoing search for how they could work in a way that "truly" honoured women and their core midwifery values.

\subsection{Maternity reforms: Taking advantage of new opportunities}

All the midwives had engaged in an array of professional development activities to ensure they could be "the very best midwife I can be" (Betty). This allowed the midwives to take advantage of the legislative changes enabling endorsement. All the midwives were eager to 
apply for endorsement even if initially they were not sure exactly where this would lead them. As Ellie recalled; "I applied for endorsement as soon as it came out... I don't know if I even intended to do it [private practice] originally... it just seemed like a natural progression".

Gaining endorsement was initially a fraught process described as "jumping through hoops". Some midwives received their endorsement relatively quickly while others waited many months. During this time the midwives started to network more broadly, forming connections with other like-minded midwives. Within these newly developed relationships, the midwives found a place to converse and share their philosophy which further validated their core values and strengthened their resolve to practice differently. Endorsement and the formation of deeper connections between midwives, created the opportunity for change that the midwives had been seeking. Candy explained how her group practice started to take shape, "So I think once I'd gotten endorsement that's when I think things progressed. I really wanted to go into private practice and these guys were moving forward so we started talking and started getting excited".

\subsection{Private midwifery practice: Risk, uncertainty and courage}

The maternity service reforms finally offered midwives an opportunity, they believed, to truly practice midwifery. Once deciding on this path, midwives took a "leap of faith" and launched themselves into the unfamiliar space of private midwifery practice. Navigating the unchartered waters of establishing a business was one of their first major hurdles. Leaving behind secured paid employment was perceived as "risky". The midwives described taking a financial risk, which affected not only themselves but their families. As Amy shared, "Well, it's taken financial investment to put into the business to start with. So taking loans, redraws 
from mortgages - that kind of thing. So we've actually risked quite a bit personally and financially for our families to do this". Along with risk came the "uncertainty" of exactly how they should and/or needed to structure the business to make it financially viable as well as ensuring compliance with legislation and Medicare requirements. Betty highlighted this aspect of setting up private practice when she said, "There was a lot of maybe we could this way, maybe we could do it that way. There was a lot of no that's not going to work ... and how are we going to make it financially viable?" The midwives also faced the challenge of lengthy negotiations for access as a visiting midwife to the public hospital which took over 12 months. An extensive consultation processes was undertaken which was described by Debbie as often feeling like "one step forward two steps back". While being part of the process was considered highly valuable to the midwives, the meetings were described as "very time consuming" and at times "really challenging".

Despite a level of trepidation, the midwives remained committed to their journey of transitioning into private practice. The desire to provide women with choices and work within a model of care that aligned with their core midwifery values, provided the midwives with the motivation to overcome the uncertainty they faced; "We really didn't know what was going to work or how we were going to do it but we knew that we had to do it" (Betty).

"Finding the courage to do what I really feel I'm meant to be doing. That was really challenging going from being in a respected position and a safe, secure, financial position, doing something that I enjoyed without really loving it and making my heart beat to taking the plunge to do something that did make my heart beat." (Debbie) 


\subsection{On the other side: Triumphs and tribulations of private practice}

Once midwives had taken the "plunge into private practice" and successfully gained visiting access, they found themselves metaphorically on the "other side". Midwives described great "joy" at being able to work within a practice context that reflected their core values whilst also continuing to face challenges resulting from system level restraints. Two subthemes emerged to describe this phenomenon.

\section{Private practice with visiting access is fantastic!}

The midwives unanimously described elation at finally being in private practice. Candy summarised the feeling of all the midwives when she said, "I love being in private practice. It is the best ever". At the heart of their enjoyment were the concepts of continuity and autonomy. Private practice and visiting access finally offered the midwives the opportunity to unequivocally support the woman's choice and provide continuity of midwifery care. The ability to remain the primary carer for women giving birth in hospital was positively reported by all the midwives. As Fleur highlighted, "I get great satisfaction from following a woman through full continuity of care and knowing that at six weeks I've done the best that I could so that she could be the best that she could be".

Having their own private practice enabled the midwives to work more flexibly. The midwives were able to organise antenatal and postnatal care at times that suited them and their families, limiting the need to work after hours or on weekends. All the midwives were on call for labour and birth when they were the primary carer, however, this was not considered problematic. As Ellie highlighted: 
"We're all on 24-hour call for our own women and we don't have rostered days off. That works really well... You actually birth less because you only birth your own women, rather than birthing your own women plus three of somebody else's".

In tandem with this was the heightened level of autonomy the midwives perceived private practice afforded them. Midwives described finally being able to use all their expertise, knowledge and skills to provide individualised care that was aligned to the woman's own preferences, needs and desires. Being able to work in this way was described as "incredibly fulfilling" (Amy). As Fleur articulated, "The autonomy, the ability to be able to work to the full scope of my practice. I think that's a benefit in itself and positive for me". This was further enhanced by gaining visiting access. Attaining visiting access provided the midwives with the ability to offer continuity of care for women booked privately with them, regardless of planned place of birth. Betty offered a simple yet poignant statement, "She (the woman) just has a glow, a very special glow that wouldn't be possible without visiting access".

Likewise, all the midwives described a change in the nature of their relationship with medical colleagues as a result of attaining visiting access. Ellie had worked in the same facility prior to going into private practice and described feeling an immediate change in the way she was treated within the hospital upon gaining visiting access:

"When I got my endorsement and got my visiting access. Straight away I could feel a difference in the way I was treated. When I'm in at the hospital, Obstetricians ask my opinion and what I think. Whereas I never used to get asked my opinion or what I thought about the care of a woman before". 
The ability to work in a more holistic way which included a three-way partnership between woman, midwife and doctor was greatly "valued" by the midwives; especially in the context of the woman developing complexities. Midwives were very positive about the realigned relationships that public sector visiting access seemed to afford them, which reflected a heightened sense of collegiality; "It [visiting access] just means we can take our clients there and look after them and care for them and the doctors work really well with us, it's really great. It's fantastic." (Candy)

\section{Still constrained by the system}

Although attaining visiting access provided midwives with an unprecedented ability to offer a woman continuity across all aspects of care, there were several factors that restricted women's access to the model. All women choosing to be admitted to hospital under a visiting midwife needed to be classified as a 'private' regardless of health insurance status in order to meet the midwives' private indemnity insurance requirements. The following extract highlights why the stipulation to be admitted privately was problematic and potentially restricted access for women; "Most of our clients do not have private health insurance so they're self-funded...It's the unknown of not knowing how much you're going to end up with having to pay at the end of the birth... That's hard" (Candy).

As a result of the financial uncertainty facing some women, some of the midwives felt obliged to develop a range of alternate service options to midwifery continuity of care. While acknowledging care from a 'known' midwife across their pregnancy, birth and early transition to motherhood was the "gold standard", midwives felt they had little choice if they wanted more women to have access to midwifery care. Some thus commenced offering women a 
'bulk billed shared care' service in which the midwife provided all community based antenatal and postnatal care services covered by Medicare, however labour and birth care would be provided by hospital employed staff. For example, Debbie explained, "We have some (women) who are bulk billed, have all of their care bulk billed. We don't attend the labour or birth obviously for shared care or bulk-billed women. It's just not financially feasible to do it unfortunately". Not everyone agreed with bulk billing, Fleur felt that such services worked to undervalue midwifery care; "The private midwives that are providing bulk-billed services for women, they're doing an injustice for themselves because they're devaluing themselves. I don't think this is any good for private midwifery. We're not going to make a living like that."

Limitations on the midwives' ability to employ newly registered midwives into the practice was also viewed as a significant constraint. The midwives expressed that the NMBA requirement for midwives to demonstrate $5000 \mathrm{hrs}$ of practice ( 3 years full time) before being able to gain endorsement as a Medicare eligible midwife was problematic and restricted who could join the practice. Without endorsement, midwives cannot access private indemnity insurance and women cannot claim a Medicare rebate. Midwives voiced deep concern that without changes to current endorsement requirements, midwifery private practices would not be able to grow.

"There's heaps of new grads that would just love to come in here. But unfortunately from a business point of view, they can't - the woman can't get Medicare rebates from them. Then it's not fair of us to ask them to see a woman where she's going to end up with more out of pocket expenses. So from a business point of view, we need them to be (endorsed)." (Ellie)

\subsection{DISCUSSION}


The aim of this small qualitative study was to explore the experiences of midwives transitioning into private practice with visiting access to a public hospital following the 2010 Australian maternity services legislative changes. Although the findings cannot be generalised and need to be interpreted with caution, given the limited numbers of midwives with visiting access in Australia and dearth of evidence on private midwifery practice, the insights gained are important and worthy of consideration. The findings raise three main topics for further discussion: midwives sought professional autonomy to practice to their full scope of practice and provide one-to-one woman centred care; private practice with visiting access enabled midwives to remain the lead care provider within a collaborative, multidisciplinary team; and further reforms need to be considered to overcome constraints to midwives practice which impacts woman's access to midwifery continuity of care.

\subsection{Professional Autonomy}

The midwives in this study demonstrated a strong commitment to providing quality woman centred care within a midwifery continuity of care model. This drove their desire for professional autonomy whereby they could work across the full scope of midwifery practice and take on the role and responsibilities of primary maternity care provider within the context of a supportive multidisciplinary team. The desire for professional autonomy expressed by the midwives in this study clearly resonates with the work of others. In the wider literature, professional autonomy is noted as a major contributing factor in job satisfaction within midwifery (Hildingsson et al., 2016; McCourt, Rayment, Rance, \& Sandall, 2014; Perdok et al., 2017). Studies conducted in the Netherlands and the United Kingdom (UK) have identified that midwives working as primary care providers had a greater sense of professional autonomy than those working within a hospital setting (McCourt et al., 2014; Perdok et al., 
2017). The findings of this study were consistent with this literature. The midwives described experiences of past employment within the hospital setting as restrictive and prohibitive of autonomous, women centred practice. Whilst the midwives described an improved sense of autonomy within the hospital based MGP, they still felt unable to put the woman at the centre of care. Most perceived this to be a consequence of the continued dominance of medicine across the maternity health care sector. It was only when the midwives moved into community based, private midwifery practice and attained visiting access, that they described a true sense of professional autonomy. Finally, the pleasure and satisfaction the midwives experienced as a result of professional autonomy is consistent with previous studies in midwifery (McCourt et al., 2014; Perdok et al., 2017) and across the broader health professions (Liu, Spector, \& Jex, 2011).

\subsection{Enhanced collaboration}

A significant finding of this study was the midwives' descriptions of the positive relationship and ability to collaborate with obstetric colleagues, which they directly attributed to visiting access. This finding is in stark contrast to the experiences of collaboration cited in other literature. For example, exploration of privately practicing and primary care midwives' experiences of collaboration with obstetricians, by an array of national and international researchers, reveals high levels of distrust and conflict (Collins, Fereday, Pincombe, Oster, \& Turnbull, 2010; Menke, Fenwick, Gamble, Brittain, \& Creedy, 2014; Romijn, Teunissen, de Bruijne, Wagner, \& de Groot, 2018). As a result, midwives commonly describe feeling isolated and unable to secure appropriate care for their clients when complexities arise (Vedam et al., 2014; Wilyman-Bugter \& Lackey, 2013). As argued by Beasley, Ford, Tracy, and Welsh (2012) and Heatley and Kruske (2011), the positive nature of collaboration (as evidenced in this 
study) is likely to have its foundation in the organisational processes and structures that underpinned the model. The midwives reported being accredited with the institution, rather than having a collaborative agreement with an individual doctor. In addition, the visiting access agreement clearly outlined the midwives' scope of practice within the institution. It is likely that the establishment of these healthy ways of working facilitated and strengthened the base for effective collaboration. As Heatley and Kruske (2011) have previously contended, attaining an agreement with the institution rather than an individual obstetrician mitigates the power imbalance that has the potential to negatively impact on collaboration. Similarly, Sullivan, Lock, and Homer (2011) purported that clearly defined roles and responsibilities within the interdisciplinary team fostered professional autonomy and midwifery agency.

The benefit of such respectful working relationships to the health and wellbeing of women and their newborns cannot be denied. Since the initial data collection for this research project was undertaken, the maternal and neonatal outcomes of over 850 woman receiving care from private practice midwives with visiting access to public hospitals in South East Queensland has been published (Fenwick et al., 2017; Wilkes, Gamble, Adam, \& Creedy, 2015). Compared to national and state data, the outcomes for women receiving care by private midwives were positive. Women experienced higher spontaneous vaginal birth rates of $79 \%$ (Fenwick et al., 2017) and 71\% (Wilkes et al., 2015) and lower rates of neonatal admission to the Newborn Care Unit (Fenwick et al., 2017; Wilkes et al., 2015).

\subsection{The need for further reform}

The maternity health reforms facilitated the opportunity for midwives to work in a different way. The midwives in this study reported that they enjoyed providing midwifery continuity of 
care as the lead carer within the context of a multidisciplinary team. The service model successfully addressed three key priorities of the Australian National Maternity Services Plan (ANMSP): increasing women's access to continuity of midwifery care; utilising a midwife's full scope of practice; and facilitating interdisciplinary collaboration within maternity care (Commonwealth of Australia, 2011). However, the findings of this small, qualitative study suggest the reforms may not have gone far enough. System-wide constraints continue impact the private practice midwives' ability to recruit newly qualified midwives and grow their practice, risking the sustainability of the model. The argument that there is a need to employ newly qualified midwives (midwives in the first one to three years post initial registration) directly into continuity of care to sustain the model is not a new concept. Recruitment of new midwives into continuity models is a widely cited strategy for growing midwifery continuity models within Australia, thus increasing women's access to these models (Cummins, DenneyWilson, \& Homer, 2016; Gray \& Smith, 2017; Hartz et al., 2012). The midwives within this study identified that the NMBA requirement of three years full time equivalent employment as a midwife prior to being endorsed for access to Medicare, precluded them from employing newly qualified midwives, subsequently creating a significant challenge to the sustainability and growth of the private practice. Without this endorsement, newly qualified midwives cannot access government supported private indemnity insurance (MIGA, 2017) or offer Medicare rebates for services. Indemnity insurance is an essential requirement of practice for all health care practitioners in Australia and the inability to access Medicare rebates may render care financially inaccessible to many women. These restrictions precluded the midwives in the study from employing newly qualified midwives who wanted, and were educated, to provide midwifery continuity in a caseload model. 
The rationale for NMBA's requirement for a midwife to have three years full time (equivalent) postgraduate experience prior to endorsement as Medicare eligible is unclear. Nationally and internationally, midwifery competency standards are informed by the International Confederation of Midwives (ICM) definition of a midwife (ICM, 2017) in which midwives are recognised as responsible and accountable professionals, able to provide care for women throughout their pregnancy, birth and early parenting continuum. As guided by the ICM global standard for midwifery education (Thompson, Fullerton, \& Sawyer, 2011), all programs leading to midwifery registration in Australia must meet the ANMAC 'midwife accreditation standards' (ANMAC, 2014). There is good evidence that the emphasis placed on continuity of care within Midwifery programs leading to registration, produces graduates who have a strong midwifery identity, want to work to their full scope of practice and aspire to gain employment in continuity models on graduation (Carter, Wilkes, Gamble, Sidebotham, \& Creedy, 2015; Clements, Davis, \& Fenwick, 2013; Cummins, Denney-Wilson, \& Homer, 2015; Dawson, Newton, Forster, \& McLachlan, 2015b; Gray, Taylor, \& Newton, 2015). In addition, there is a growing body of evidence suggesting that ensuring newly qualified midwives can move straight into continuity models may well address the high levels of dissatisfaction and attrition witnessed in this group when they move into the early years of their career (Clements et al., 2013; Creedy, Sidebotham, Gamble, Pallant, \& Fenwick, 2017; Cummins et al., 2016; Dawson et al., 2015b; Gray \& Smith, 2017; Hartz et al., 2012).

\subsection{CONCLUSION AND RECOMMENDATIONS}

This small but insightful qualitative study has highlighted midwives' experiences of transitioning into private practice with visiting access within the Australian maternity care context. Six privately practicing midwives with visiting access represents a significant 
proportion due to the very small numbers of midwives practicing in this way. Findings of this study highlight that private practice with visiting access provided midwives with the ability to work as lead care professionals, provide woman centred care and be supported by a collaborative network of health care professions. However, midwives continued to face structural constraints that limited women's access and threaten the sustainability of midwifery models of care. The current need of a minimum of three years full time experience to meet requirements for endorsement within Australia, needs to be critically explored and strategies for supporting newly qualified midwives to transition into private practice investigated. Health care services must improve pathways for visiting access as a crucial step towards achieving effective collaboration between privately practicing midwives and hospital-based care providers. Further research involving privately practicing midwives and key stakeholders including women and public and private health sectors, is required to capture health outcomes and fiscal impact for women and their babies, midwives and health service provision.

Acknowledgements and disclosures: The authors would like to thank the midwives who took part in this research project. We would also like to acknowledge Tania Fleming for conducting the interviews with the private practice midwives.

This research did not receive any specific grant from funding agencies in the public, commercial, or not-for-profit sectors. 


\section{References}

ANMAC. (2014). Midwife Accreditation Standards 2014. Retrieved from http://www.anmac.org.au/sites/default/files/documents/ANMAC_Midwife_Accreditation_S tandards_2014.pdf.

Australian Institute of Health and Welfare. (2016). Nursing and Midwifery workforce. Retrieved from http://www.aihw.gov.au/workforce/nursing-and-midwifery/midwives/

Beasley, S., Ford, N., Tracy, S. K., \& Welsh, A. W. (2012). Collaboration in Maternity Care is achievable and practical. Australian and New Zealand Journal of Obstetrics and Gynaecology, 52(6), 576-581. doi:10.1111/ajo.12003

Carter, A. G., Wilkes, E., Gamble, J., Sidebotham, M., \& Creedy, D. K. (2015). Midwifery students' experiences of an innovative clinical placement model embedded within midwifery continuity of care in Australia. Midwifery, 31(8), 765-771. doi:http://dx.doi.org/10.1016/j.midw.2015.04.006

Clements, V., Davis, D., \& Fenwick, J. (2013). Continuity of Care: Supporting New Graduates to Grow Into Confident Practitioners. International Journal of Childbirth, 3(1), 3-12. doi:10.1891/2156-5287.3.1.3

Collins, C. T., Fereday, J., Pincombe, J., Oster, C., \& Turnbull, D. (2010). An evaluation of the satisfaction of midwives' working in midwifery group practice. Midwifery, 26(4), 435-441. doi:10.1016/j.midw.2008.09.004

Commonwealth of Australia. (2009). Improving services in Australia: The report of the national maternity services review. Retrieved from https://www.health.gov.au/internet/main/publishing.nsf/content/624EF4BED503DB5BCA25 7BF0001DC83C/\$File/Improving\%20Maternity\%20Services\%20in\%20Australia\%20\%20The\%20Report\%20of\%20the\%20Maternity\%20Services\%20Review.pdf

Commonwealth of Australia. (2011). National Maternity Services Plan 2010. Retrieved from https://www.health.gov.au/internet/main/publishing.nsf/Content/8AF951CE492C799FCA25 7BF0001C1A4E/\$File/maternityplan.pdf.

Creedy, D. K., Sidebotham, M., Gamble, J., Pallant, J., \& Fenwick, J. (2017). Prevalence of burnout, depression, anxiety and stress in Australian midwives: a cross-sectional survey. BMC Pregnancy Childbirth, 17(1), 13. doi:10.1186/s12884-016-1212-5

Cummins, A. M., Denney-Wilson, E., \& Homer, C. S. E. (2015). The experiences of new graduate midwives working in midwifery continuity of care models in Australia. Midwifery, 31(4), 438444. doi:10.1016/j.midw.2014.12.013

Cummins, A. M., Denney-Wilson, E., \& Homer, C. S. E. (2016). The challenge of employing and managing new graduate midwives in midwifery group practices in hospitals. Journal of Nursing Management, 24(5), 614-623. doi:10.1111/jonm.12364

Davis, D. (1995). Independent practice: A critical analysis and a personal journey. Australian College of Midwives Incorporated Journal(March), 9-12.

Dawson, K., Newton, M., Forster, D., \& McLachlan, H. (2015a). Caseload midwifery in Australia: What access do women have? Women and Birth, 28(S12). doi: 10.1016/j.wombi.2015.07.048

Dawson, K., Newton, M., Forster, D., \& McLachlan, H. (2015b). Exploring midwifery students' views and experiences of caseload midwifery: A cross-sectional survey conducted in Victoria, Australia. Midwifery, 31(2), e7-e15. doi:10.1016/j.midw.2014.09.007

Fenwick, J., Brittain, H., \& Gamble, J. (2017). Australian private midwives with hospital visiting rights in Queensland: Structures and processes impacting clinical outcomes. Women and Birth. doi:10.1016/j.wombi.2017.05.001

Gamble, J. (1993a). Becoming an independent midwife. The Queensland Nurse(March/April), 14-15.

Gamble, J. (1993b). Opportnities and obstacles for independent midwives. The Queensland Nurse(May/June), 19-20. 
Gray, J., \& Smith, R. M. (2017). Any action? Reflections on the Australian Midwifery Action Project. Women Birth, 30(3), 177-183. doi:10.1016/j.wombi.2017.02.008

Gray, J., Taylor, J., \& Newton, M. (2015). Embedding continuity of care experiences: An innovation in midwifery education. Midwifery, 33, 40-42. doi:10.1016/j.midw.2015.11.014

Hartz, D. L., White, J., Lainchbury, K. A., Gunn, H., Jarman, H., Welsh, A. W., . . Tracy, S. K. (2012). Australian maternity reform through clinical redesign. Australian Health Review, 36(2), 6-6.

Heatley, M., \& Kruske, S. (2011). Defining collaboration in Australian maternity care. Women and Birth, 24(2), 53-57. doi:https://doi.org/10.1016/j.wombi.2011.02.002

Hildingsson, I., Gamble, J., Sidebotham, M., Creedy, D. K., Guilliland, K., Dixon, L., . . Fenwick, J. (2016). Midwifery empowerment: National surveys of midwives from Australia, New Zealand and Sweden. Midwifery, 40, 62-69. doi:10.1016/j.midw.2016.06.008

ICM. (2017). ICM International definition of the midwife. Retrieved from https://www.internationalmidwives.org/assets/files/definitions-files/2018/06/engdefinition_of_the_midwife-2017.pdf

Jenkin, S. (2013). What do Hobbits and eligible midwives in private practice have in common? Midwifery News(November), 16-17.

Liu, C., Spector, P., \& Jex, S. (2011). The relation of job control with job strains: A comparison of multiple data sources. Journal of Occupational and Organisational Psychology, 78, 325-336.

McCourt, C., Rayment, J., Rance, S., \& Sandall, J. (2014). An ethnographic organisational study of alongside midwifery units: a follow-on study from the Birthplace in England programme. Helath Services and Delivery Research, 2(7). doi:10.3310/hsdr02070

Menke, J., Fenwick, J., Gamble, J., Brittain, H., \& Creedy, D. K. (2014). Midwives' perceptions of organisational structures and processes influencing their ability to provide caseload care to socially disadvantaged and vulnerable women. Midwifery, 30(10), 1096-1103. doi:10.1016/j.midw.2013.12.015

MIGA. (2017). Insurance for Eligible Midwives in private practice. Retrieved from https://www.miga.com.au/MIGA/media/MIGA/.../2017-midwives-policy-wording.pdf

National Health and Medical Research Council. (2014). National statement on ethical conduct in human research (2007). Retrieved from http://www.nhmrc.gov.au/_files_nhmrc/publications/attachments/e72_national_st atement_march_2014_141126.pdf

Neergaard, M. A., Olesen, F., Andersen, R. S., \& Sondergaard, J. (2009). Qualitative description - the poor cousin of health research? BMC Med Res Methodol, 9, 52. doi:10.1186/1471-2288-9-52

NMBA. (2017). Nursing and Midwifery Board of Australia Registration Standard: Endorsement for scheduled medicines for midwives. Retrieved from http://www.nursingmidwiferyboard.gov.au/Registration-Standards/Endorsement-forscheduled-medicines-for-midwives.aspx.

NMBA. (2019). Nurse and Midwife Registrant Data. Reporting period: 1 January 2019 - 31 March 2019.

Perdok, H., Cronie, D., van der Speld, C., van Dillen, J., de Jonge, A., Rijnders, M., . . Verhoeven, C. J. (2017). Experienced job autonomy among maternity care professionals in The Netherlands. Midwifery, 54, 67-72. doi:10.1016/j.midw.2017.07.015

Romijn, A., Teunissen, P. W., de Bruijne, M. C., Wagner, C., \& de Groot, C. J. M. (2018). Interprofessional collaboration among care professionals in obstetrical care: are perceptions aligned? BMJ Qual Saf, 27(4), 279-286. doi:10.1136/bmjqs-2016-006401

Sandall, J., Soltani, H., Gates, S., Shennan, A., \& Devane, D. (2016). Midwife-led continuity models versus other models of care for childbearing women. Cochrane Database Syst Rev, 4, CD004667. doi:10.1002/14651858.CD004667.pub5

Sandelowski, M. (2000). Whatever Happened to Qualitative Description? Research in Nursing and Health, 23, 334-340. 
Smith, S. (1994). Becoming an independent homebirth midwife. Australian College of Midwives Incorporated Journal(Dec), 27-30.

Sullivan, K., Lock, L., \& Homer, C. (2011). Factors That Contribute to midwives staying in midwifery: A study In one area health service in New South Wales, Australia. Midwifery, 27, 331-335.

Thompson, J. B., Fullerton, J. T., \& Sawyer, A. J. (2011). The International Confederation of Midwives: Global Standards for Midwifery Education (2010) with Companion Guidelines. Midwifery, 27(4), 409-416. doi:http://dx.doi.org/10.1016/j.midw.2011.04.001

Tracy, S. K., Welsh, A., Hall, B., Hartz, D., Lainchbury, A., Bisits, A., .. Tracy, M. B. (2014). Caseload midwifery compared to standard or private obstetric care for first time mothers in a public teaching hospital in Australia: a cross sectional study of cost and birth outcomes. BMC Pregnancy and Childbirth, 14(1), 46. doi:10.1186/1471-2393-14-46

Vedam, S., Leeman, L., Cheyney, M., Fisher, T. J., Myers, S., Low, L. K., \& Ruhl, C. (2014). Transfer from planned home birth to hospital: improving interprofessional collaboration. J Midwifery Womens Health, 59(6), 624-634. doi:10.1111/jmwh.12251

Wilkes, E., Gamble, J., Adam, G., \& Creedy, D. K. (2015). Reforming maternity services in Australia: Outcomes of a private practice midwifery service. Midwifery, 31(10), 935-940. doi:http://dx.doi.org/10.1016/j.midw.2015.05.006

Wilyman-Bugter, M., \& Lackey, T. (2013). Midwives' experiences of home birth transfer. EvidenceBased Midwifery (Royal College of Midwives), 11(1), 28. 
Table 1: Participant characteristics

\begin{tabular}{|c|c|c|c|}
\hline \multirow[t]{2}{*}{ Characteristic } & \multirow{2}{*}{$\begin{array}{l}\text { Variation } \\
\text { characteristics }\end{array}$} & \multicolumn{2}{|c|}{ Number of participants } \\
\hline & & $\mathrm{N}=6$ & $\%$ \\
\hline \multirow[t]{2}{*}{ Age } & $35-45$ years & 3 & $50 \%$ \\
\hline & $45-55$ years & 3 & $50 \%$ \\
\hline Gender & Female & 6 & $100 \%$ \\
\hline Duration of midwifery & $10-15$ years & 3 & $50 \%$ \\
\hline \multirow[t]{2}{*}{ experience } & $15-20$ years & 2 & $30 \%$ \\
\hline & $20-25$ years & 1 & $20 \%$ \\
\hline \multirow[t]{2}{*}{$\begin{array}{l}\text { Midwifery education- } \\
\text { qualification }\end{array}$} & $\begin{array}{l}\text { Nursing qualifications } \\
\text { followed by midwifery } \\
\text { qualifications }\end{array}$ & 5 & $80 \%$ \\
\hline & $\begin{array}{l}\text { Undergraduate midwifery } \\
\text { qualifications }\end{array}$ & 1 & $20 \%$ \\
\hline Postgraduate education & $\begin{array}{l}\text { Postgraduate studies in } \\
\text { midwifery }\end{array}$ & 6 & $100 \%$ \\
\hline Location of initial midwifery & Australia & 4 & $60 \%$ \\
\hline \multirow[t]{2}{*}{ registration } & New Zealand & 1 & $20 \%$ \\
\hline & United Kingdom & 1 & $20 \%$ \\
\hline $\begin{array}{l}\text { Previous experience within } \\
\text { midwifery continuity of care } \\
\text { model }\end{array}$ & Yes & 6 & $100 \%$ \\
\hline
\end{tabular}


Table 2: Example of emerging concept informing the theme 'with system versus with woman: a misaligned practice context

\begin{tabular}{|c|c|c|}
\hline Data & Specific Concepts & Theme \\
\hline $\begin{array}{l}\text { "I felt like I'd had my hands cut } \\
\text { off when I came to Australia } 10 \\
\text { years ago. You can't suture, } \\
\text { you can't cannulate, I can't } \\
\text { make a decision, I'm not } \\
\text { respected by any doctors." } \\
\text { (Ellie) }\end{array}$ & $\begin{array}{l}\text { - } \text { Felt like hands cut off } \\
\text { - } \text { Can't suture } \\
\text { - } \text { Can't cannulate } \\
\text { - } \quad \text { Can't make decision } \\
\text { - } \quad \text { Not respected }\end{array}$ & \\
\hline $\begin{array}{l}\text { "In hospital we're very much } \\
\text { not allowed to do things. } \\
\text { You're not allowed to put in a } \\
\text { drip, that's a doctor's job. } \\
\text { You're not allowed to suture, } \\
\text { that's the doctor's job. You're } \\
\text { not allowed to write } \\
\text { prescriptions, you're not } \\
\text { allowed to take blood" (Candy) }\end{array}$ & $\begin{array}{l}\text { - Not allowed to suture, } \\
\text { cannulate, write script } \\
\text { - 'doctors job' not midwife }\end{array}$ & \\
\hline $\begin{array}{l}\text { "I was hardly ever allowed to } \\
\text { do anything" (Fluer) }\end{array}$ & $\begin{array}{l}\text { - Can't work to my full } \\
\text { scope }\end{array}$ & \\
\hline $\begin{array}{l}\text { "It's - that the hospital or the } \\
\text { institutions at the centre of } \\
\text { care or the doctors at the - or } \\
\text { the midwives at the centre of } \\
\text { care even - and that the } \\
\text { woman's not." (Ellie) }\end{array}$ & $\begin{array}{l}\text { - Systems focussed care } \\
\text { - Woman not at centre of } \\
\text { care }\end{array}$ & $\begin{array}{l}\text { 'With system' versus } \\
\text { 'with woman': A } \\
\text { misaligned practice } \\
\text { context }\end{array}$ \\
\hline $\begin{array}{l}\text { But just felt like I couldn't be a } \\
\text { midwife in Australia because } \\
\text { the model was so fragmented } \\
\text { and wasn't anything like what I } \\
\text { thought being a midwife was } \\
\text { all about" (Debbie) }\end{array}$ & $\begin{array}{l}\text { - Can't be a 'midwife' in } \\
\text { fragmented model }\end{array}$ & \\
\hline
\end{tabular}

